\title{
The impact of visceral fat and levels of vitamin D on coronary artery calcification
}

\author{
Isa Galvão Rodrigues ${ }^{*}$ (1), Claudia Porto Sabino Pinho (1), Dário Sobral Filho 1,2 (1), \\ Ana Paula Dornelas Leão ${ }^{1}$ (D), Maria Cristina Monterio Oliveira' ${ }^{1}$, Gerssica Pina Barbosa ${ }^{3}$ (D),

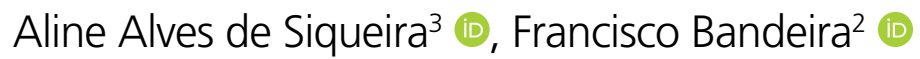

\begin{abstract}
SUMMARY
OBJECTIVE: To evaluated calcification of the coronary arteries and its association with visceral fat and 25-hydroxyvitamin D (25(OH)D) serum levels.

METHODS: A cross sectional study involving 140 individuals without any previous diagnosis of cardiovascular disease. A biochemical analysis of vitamin D serum levels was carried out, as well as computed tomography to measure coronary artery calcium score and visceral adipose tissue.

RESULTS: The mean age of the individuals was 55.9 ( \pm 12.4$)$. Coronary artery calcium was observed in $40.7 \%$ of the population. Vitamin D presented median serum levels of $30.4 \mathrm{ng} / \mathrm{ml}$ (IQ24.5-39.1), with 14,1 and $33.7 \%$ of the individuals presenting deficiency and insufficiency, respectively. In the univariate analysis, the calcium score was more prevalent in aged patients $(p<0.01)$, in hypertensive individuals $(p<0.01)$, in diabetics ( $p=0.02)$, and in those with a higher concentration of VAT $(p=0.02)$. In the adjusted analysis, it was found that the highest concentration of VAT (OR: $4.0 ; 95 \% \mathrm{Cl} 1.4-11.7)$, hypertension (OR: 4.8; $95 \% \mathrm{Cl} 1.5-15.3$ ), and age (OR: 10.4; $95 \% \mathrm{Cl} 3.9-27.6)$ were predictors of subclinical atherosclerosis, regardless of body mass index, diabetes, and $25 \mathrm{OHD}$.

CONCLUSIONS: Excess visceral fat was associated with subclinical atherosclerosis, regardless of other risk factors for cardiovascular disease. Serum levels of 25OHD were not associated with CAD in its early stages.

KEYWORDS: Cardiovascular diseases. Vitamin D. Obesity. Vascular calcification.
\end{abstract}

\section{INTRODUCTION}

Cardiovascular diseases (CVD) are highly prevalent worldwide. They are an important cause of morbidity and the main cause of mortality in Brasil and the world ${ }^{1}$. CVD have insidiously develop over decades, and their first signs can be fatal or highly limiting. Thus, identifying and modifying the pathological process in the initial subclinical stages of CVD can be clinically challenging ${ }^{2}$.

Calcification of coronary arteries (CCA), also known as subclinical atherosclerosis, is currently characterized as a dynamic process of biomineralization, complexly regulated and closely related to the degree of inflammatory activity ${ }^{3,4}$. Several bone remodeling regulators, such as osteocalcin, hydroxyapatite crystals, osteopontin, bone morphogenetic protein 2, osteoprotegerin, leptin, and oxidized lipids, and factors related to calcium sensor have been described in calcified atherosclerotic lesions ${ }^{4}$.

Vitamin D plays an important role in regulating mineral and bone metabolism ${ }^{5}$. A recent meta-analysis correlated low vitamin $\mathrm{D}$ levels with increased cardiovascular risk ${ }^{5}$, suggesting that hypovitaminosis $\mathrm{D}$ may be an undervalued risk factor for

\footnotetext{
1 Universidade de Pernambuco, Pronto Socorro Cardiológico Universitário de Pernambuco - Recife (PE), Brasil.

2Universidade de Pernambuco, Faculdade de Ciências Médicas - Recife (PE), Brasil.

${ }^{3}$ Faculdade São Miguel - Recife (PE), Brasil.

*Corresponding author: isagalvao@gmail.com

Conflicts of interest: the authors declare there is no conflicts of interest. Funding: none.

Received on August 10, 2020. Accepted on September 20, 2020.
} 
CVD. Evidence accumulated in recent decades indicates that the beneficial role of vitamin $\mathrm{D}$ for cardiovascular health involves genomic mechanisms responsible for non-classical effects of vitamin $\mathrm{D}$ and are mainly mediated by its active forms, $1 \alpha$ 25-hydroxyvitamin $\mathrm{D}(1 \alpha, 25(\mathrm{OH}) \mathrm{D})$ and 1.25-hydroxyvitamin $\mathrm{D}(1.25(\mathrm{OH}) \mathrm{D})$, interacting with its intracellular receptor ${ }^{6,7}$.

Excess body fat is related to many diseases, including CVD and cerebrovascular disease. However, evidence from the literature suggests that, compared to total body fat, fat deposited in the abdominal region is a better predictor of high coronary risk $^{8,9}$. Furthermore, visceral adipose tissue (VAT) has been shown to predict differentiated cardiometabolic risk ${ }^{10}$.

Thus, this study aimed to evaluate the association between CCA, measured by the calcium score, and serum $25(\mathrm{OH}) \mathrm{D}$ and VAT levels.

\section{METHODS}

The study protocol was approved by the Ethics and Research Committee on Human Beings of Universidade de Pernambuco. Patients aged $\geq 35$ years without a prior history of heart disease who were consulted in the outpatient department between June 2014 and October 2015 were included. Individuals with hepatitis and/or splenomegaly, ascites, recent abdominal surgery, chronic renal failure, and carriers of hypothyroidism or hyperthyroidism and pregnant women were excluded. Informed consent was obtained from all participants.

CCA (the right coronary aorta, left coronary trunk, anterior descending artery and its branches, and circumflex artery and its branches) was classified as absent $(0)$ or present $(>0)$ and evaluated by computed tomography $(\mathrm{CT})$ with multiple detectors. Lesions with a minimum density of 130 Hounsfield units (HU) and a minimum area of $0.5 \mathrm{~mm}^{2}$ were detected.

VAT levels were evaluated using non-contrast abdominal CT (Philips Brilliance 10 Slice CT Scanner, VMI Indústria e Comércio Ltda, Lagoa Santa, MG, Brasil) by a single observer trained in the study protocol after a 4-hour complete fasting. Density values between -50 and $-250 \mathrm{HU}$ were used to identify adipose tissue. A high volume of visceral tissue and subcutaneous adipose tissue (SAT) was considered when the value was above the $75^{\text {th }}$ percentile of the distribution (VAT $\geq 316.0$ $\mathrm{cm}^{3}$ and $\left.\mathrm{SAT} \geq 536.2 \mathrm{~cm}^{3}\right)$.

The dosage of $25(\mathrm{OH}) \mathrm{D}$ was evaluated using the competitive chemiluminescent immunoassay method. Serum 25(OH)D levels $\leq 20 \mathrm{ng} / \mathrm{mL}$, between 21 and $29 \mathrm{ng} / \mathrm{ml}$, and $\geq 30 \mathrm{ng} / \mathrm{mL}$ indicated deficiency, insufficiency, and sufficiency, respectively9.

Among the anthropometric variables, body mass index (BMI) and abdominal circumference (AC) were considered. BMI was classified according to the classification proposed by the World
Health Organization, and the measurement of $A C$ was obtained at the midpoint between the last rib and the iliac crest.

Data were analyzed using the Statistical Package for Social Sciences, version 22.0. Associations between categorical variables were evaluated by the $\chi^{2}$ test. Variables that reached statistical significance $(\mathrm{p} \leq 0.20)$ in the univariate analysis were subsequently included in the logistic regression model. The significance level was set at $\mathrm{p}<0.05$ for all statistical analyses.

\section{RESULTS}

A total of 161 patients were eligible for the study. However, 6 patients refused to participate and 15 did not undergo all the proposed tests. Thus, a total of 140 patients were finally included.

The mean patient age was $55.9 \pm 12.36$ years, and $72.2 \%$ patients were women, $72 \%$ patients were non-white, and $92.3 \%$ patients had low socioeconomic status. Furthermore, 28.9\% patients had diabetes and $63.4 \%$ had hypertension (Table 1 ).

The presence of CCA was observed in $40.7 \%$ of the studied population. The median serum vitamin D levels were 30.4 (IQR 24.5-39.1) ng/mL; $12.9 \%$ of patients had deficient levels and $33.7 \%$ had insufficient levels. The median visceral compartment volume was $277.38 \pm 95.75 \mathrm{~cm}^{3}$ (Figure 1).

In univariate analysis, the prevalence of CCA was higher in aged $(\mathrm{p}<0.01)$, hypertensive $(\mathrm{p}<0.01)$, and diabetic $(\mathrm{p}=0.02)$ individuals and in those with a higher concentration of VAT

Table 1. Clinical, anthropometric and demographic characteristics of the study patients.

\begin{tabular}{l|c|c}
\multicolumn{1}{l|}{} & $\mathrm{n}$ & $\%$ \\
\hline Women & 101 & 72.2 \\
\hline Age $\geq 60$ years & 56 & 39.6 \\
\hline Race White & 40 & 28.0 \\
\hline \multicolumn{2}{|l}{ Socioeconomic status } \\
\hline \multicolumn{1}{|l}{ High status } & 11 & 7.7 \\
\hline Low status & 129 & 92.3 \\
\hline Diabetes Mellitus & 40 & 28.9 \\
\hline Hypertension & 89 & 63.4 \\
\hline Body Mass Index & 36 & 25.9 \\
\hline Normal Weight & 104 & 74.1 \\
\hline Overweight & 121 & 86.6 \\
\hline \multicolumn{2}{|l}{ High Waist Circumference }
\end{tabular}

Socioeconomic status defined by Brasilian Economic Classification Criteria: High social economic stratum: A1, A2 e B1. Low social economic stratum: B2, C1, C2, D e E.BMI: Body Mass Index. Normal weight: 18.5 a $24.9 \mathrm{~kg} / \mathrm{m}^{2}$. Overweight: $\geq 30 \mathrm{~kg} / \mathrm{m}^{2}$. High Waist Circumference: $>80 \mathrm{~cm}$ for women e $>94 \mathrm{~cm}$ for men. 
$(\mathrm{p}=0.02)$. No association was found between CCA and vitamin D status ( $\mathrm{p}=0.25$; Table 2).

Results of the logistic regression model analysis showed that individuals in the $\geq 75$ percentile of VAT levels had a four times higher prevalence of CCA than those with $<75$ percentile of TAV levels (odds ratio [OR]: 4.0; 95\%CI 1.4-11.7). Hypertension (OR: 4.8 ; 95\%CI 1.5-15.3) and age $>60$ years (OR: 10.4; 95\%CI 3.9-27.6) were associated with CCA after adjusting for confounding variables such as gender, presence of diabetes, SAT, and BMI (Table 3).

\section{DISCUSSION}

The detection of CCA, also known as subclinical atherosclerosis, has been proposed as a strategy to improve the identification of individuals at high risk of cardiovascular events, especially those in which traditional screening tools can underestimate the risk. This allows the implementation of more effective prevention measures.

The prevalence of CCA in this study (40.7\%) was similar to that reported in the Third Generation of the Framingham Heart Study cohort study $(42.5 \%)^{10}$. Our results reinforce the findings of a high prevalence of CCA, even in populations without a previous history of CCA, which indicates that a high number of individuals are at risk for cardiovascular events. Based on the results of several studies, the main cardiological guidelines recommend the use of CCA for risk stratification in asymptomatic patients.

As described in previous studies, vascular calcification is more prevalent in aged, hypertensive, and diabetic individu$\mathrm{als}^{11}$. This is also in line with the results reported by Julie Anne Hof et al. ${ }^{12}$ in a population-based study including 35,500 participants. Given that the atherosclerotic process usually occurs over several years, aging is one of the most consistent and robust factors involved in the incidence of CVD.

Results of univariate and multivariate analyses showed an increased prevalence of CCA among hypertensive individuals, consistent with the results of previous studies ${ }^{13,14}$. Although the inter-relationship between hypertension, coronary atherosclerosis, and calcification is not fully understood, some mechanisms, such as the induction of trauma to the arterial wall, have been proposed. Trauma to the arterial wall has been suggested to induce the expression of osteopontin, a protein involved in mineralization.

The prevalence of vitamin $\mathrm{D}$ deficiency/insufficiency in our study (33.0\%) was lower than that reported in other studies in the Brazilian population-Bandeira et al. ${ }^{15}$ reported a prevalence of $66.7 \%$ and Maeda et al. ${ }^{16}$ reported a prevalence of

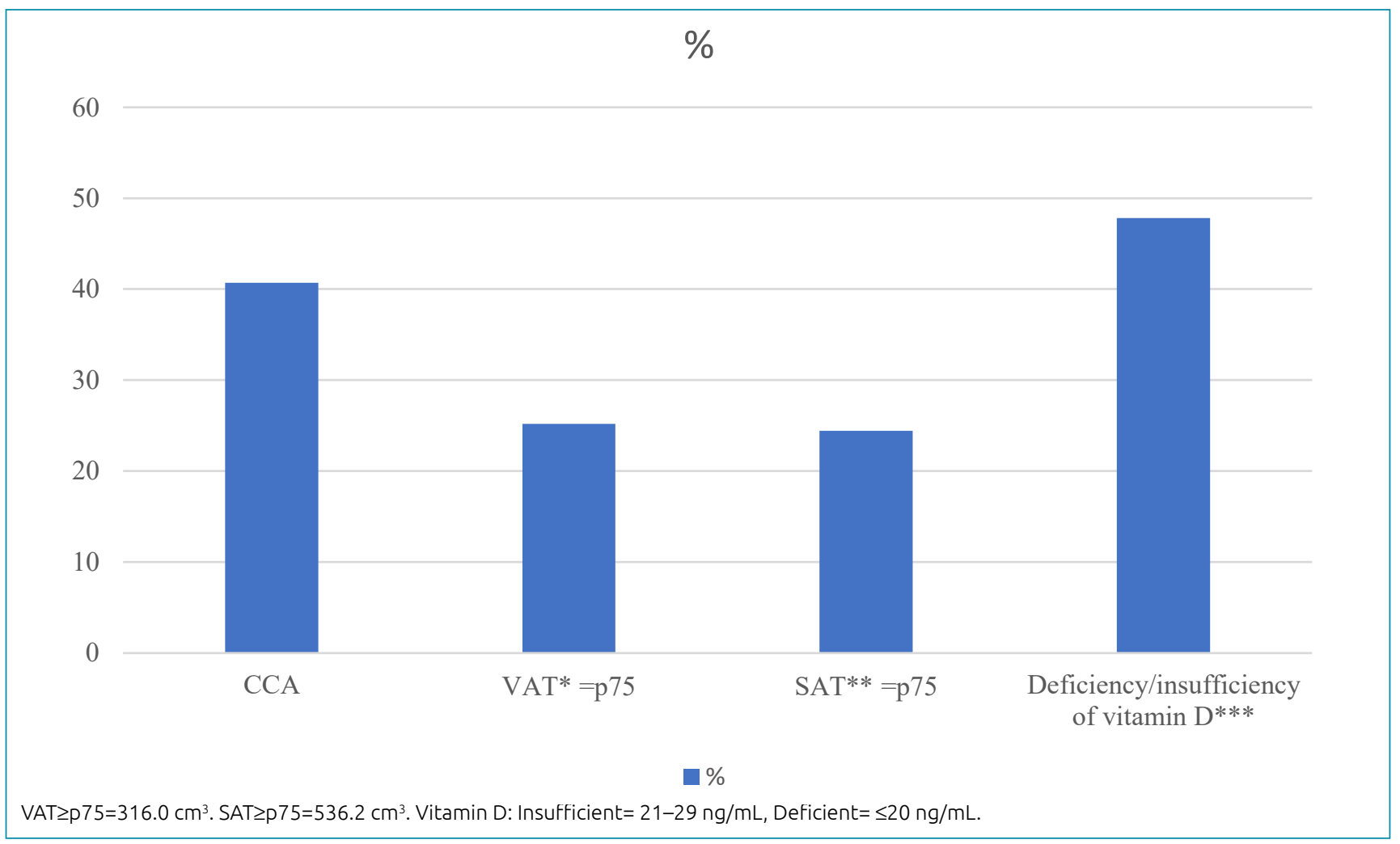

Graphic 1. Calcification of coronary arteries, visceral adipose tissue, subcutaneous adipose tissue and deficiency/insufficiency of vitamin $\mathrm{D}$. 
$73 \%$. Differences in the studied population could explain the lower prevalence of vitamin D deficiency/insufficiency in our study. Both abovementioned studies ${ }^{15,16}$ included individuals with a higher mean age (69.4 and 79.6 years, respectively) than those in the present one (55.9 years) and some institutionalized patients; hence, their exposure to sunlight may have been limited. In addition, aging may cause decreased intestinal absorption and impaired hydroxylation in the liver and kidneys.

A relationship between vitamin D levels and CVD has been proposed, but it has not been well established. Although we have not evidenced this association in our findings, some authors have shown that low serum $25(\mathrm{OH}) \mathrm{D}$ levels were related to increased carotid intima-media thickness ${ }^{17}$ and CCA in adults without symptoms of $\mathrm{CVD}^{18}$. An in vitro study showed that vitamin $\mathrm{D}$ inhibited the proliferation of vascular smooth muscle cells ${ }^{19}$. Another study showed that low serum vitamin D levels were associated with activation of the renin-angiotensin system ${ }^{20}$.
Our study cohort included a high percentage of patients who were overweight $(74.1 \%)$, those with abdominal obesity (86.6\%), and those with a higher mean VAT. Only excess VAT was associated with CCA in univariate and multivariate analyses, increasing the chance of presenting CCA by four times compared to individuals with a lower VRT concentration.

Table 3. Multivariable logistic regression analysis for the association factors with calcification of coronary arteries in adults without a previous history of cardiovascular disease.

\begin{tabular}{l|c|c|c} 
& OR & $95 \% \mathrm{Cl}$ & p-value \\
\hline VAT P75 & 4.0 & $1.4-11.7$ & 0.01 \\
\hline Age $\geq 60$ years & 10.4 & $3.9-27.6$ & $<0.00$ \\
\hline Hypertension & 4.8 & $1.5-15.3$ & $<0.00$ \\
\hline
\end{tabular}

OR: Odds Ratio; 95\%Cl: confidence intervals; VAT: Visceral adipose tissue. Adjustments includes: VAT, subcutaneous adipose tissue, BMI, gender, age, hypertension, diabetes mellitus.

Table 2. Association between calcification of coronary arteries and variables clinical, anthropometric, demographic, lifestyle, abdominal fat (visceral and subcutaneous) and vitamin D levels.

\begin{tabular}{|c|c|c|c|c|}
\hline & $\mathrm{N}$ & CCA Absent \% & CCA Present $\%$ & p-value* \\
\hline \multicolumn{5}{|l|}{ Age } \\
\hline$\geq 60$ years & 56 & 21.8 & 69.8 & $<0.01$ \\
\hline \multicolumn{5}{|l|}{ Gender } \\
\hline Male & 39 & 52.6 & 47.4 & \multirow{2}{*}{0.06} \\
\hline Female & 101 & 67.3 & 32.7 & \\
\hline Hypertension & 140 & 48.3 & 51.7 & $<0.01$ \\
\hline Diabetes mellitus & 140 & 47.5 & 52.5 & 0.02 \\
\hline \multicolumn{5}{|l|}{ Body mass index } \\
\hline Normal weight & 36 & 27.5 & 27.1 & \multirow{2}{*}{0.81} \\
\hline Overweight & 94 & 72.5 & 72.9 & \\
\hline Abdominal obesity & 95 & 57.9 & 42.1 & 0.28 \\
\hline \multicolumn{5}{|l|}{ Visceral adipose tissue } \\
\hline Percentile $<$ P75 & 105 & 71.1 & 29.0 & \multirow{2}{*}{0.02} \\
\hline Percentile $\geq 75$ & 35 & 40.6 & 59.4 & \\
\hline \multicolumn{5}{|c|}{ Subcutaneous adipose tissue } \\
\hline Percentile <P75 & 106 & 53.5 & 46.8 & \multirow{2}{*}{0.20} \\
\hline Percentile $\geq 75$ & 34 & 46.4 & 53.2 & \\
\hline \multicolumn{5}{|l|}{ Vitamin D } \\
\hline Deficient & 13 & 53.8 & 46.2 & \multirow{3}{*}{0.25} \\
\hline Insufficient & 31 & 54.8 & 45.2 & \\
\hline Sufficient & 48 & 62.5 & 37.5 & \\
\hline
\end{tabular}

CCA: Calcification of coronary arteries. ${ }^{*} \chi^{2}$ test. 
Corroborating our findings, the NeoStudy ${ }^{21}$ found an association between subclinical atherosclerosis, measured by the thickness of the carotid artery intima media, and vertical auto profile cholesterol test results in men and women aged 45-65 years. Similar findings were obtained in the Multi-Detector Computed Tomgraphy study, which included individuals with a mean of 50 years; the study reported a lower risk of subclinical atherosclerosis in patients with lower values of visceral adiposity ${ }^{22}$.

The deleterious effect of increased visceral fat concentration appears to be linked to the release of free fatty acids into liver circulation, which stimulates the release of apolipoprotein $\mathrm{B}$, thus promoting insulin resistance and leading to increased plasma glucose levels, with consequent endothelial dysfunction ${ }^{23}$. Other mechanisms have also been proposed, such as increased release of inflammatory cytokines, adiponectin, interleukin 6 , and inhibitor of activation of plasminogen 1 by VAT, which appear to be involved in the genesis of the atherogenic process.

This finding reinforces the importance of assessing the distribution of body fat rather than global obesity while tracking the risk of CVD. This is in line with the observations reported by See et al., who provided evidence of a correlation of CCA with VAT, but not with BMI ${ }^{24}$.

Our study has some limitations. First, the study had a cross-sectional design. Second, the relatively small sample size and the larger proportion of women may limit the generalization of results. However, the use of CT, considered the "gold standard" for measuring the visceral compartment, is an important strength of our study.

\section{CONCLUSIONS}

Excess visceral fat is associated with subclinical atherosclerosis, independent of other risk factors of CVD. Here, serum 25(OH) $\mathrm{D}$ levels were not associated with CCA in its early stages.

More research is needed to achieve more definitive conclusions on the association between these parameters and CCA. However, it is important in clinical practice to adopt strategies for the analysis of the intra-abdominal fat composition as a method of CCA risk screening.

\section{AUTHORS" CONTRIBUTIONS}

IGR: Conceptualization, Data Curation, Formal Analysis, Writing - Original Draft. CPSP: Conceptualization, Data Curation, Formal Analysis, Writing - Review \& Editing. DSF: Conceptualization, Writing - Review \& Editing. APDL: Data Curation, Validation. MCMO: Data Curation, Validation. GPB: Data Curation, Validation. AAS: Data Curation, Validation. FB: Conceptualization, Writing - Review \& Editing.

\section{REFERENCES}

1. Nichols M, Townsend N, Scarborough P, Rayner M. Cardiovascular disease in Europe 2014: epidemiological update. Eur Heart J. 2014;35(42):2950-9. https://doi.org/10.1093/eurheartj/ ehu378

2. Kataoka Y, Wolski K, Uno K, Puri R, Tuzcu EM, Nissen SE, et al. Spotty calcification as a marker of accelerated progression of coronary atherosclerosis: insights from serial intravascular ultrasound. J Am Coll Cardiol. 2012;59(18):1592-7. https:// doi.org/10.1016/j.jacc.2012.03.012

3. Bobryshev YV. Targeting vascular calcification: up-date. Curr Pharm Des. 2014;20(37):5799-800. https://doi.org/10.2174 /1381612820666140212210821

4. McCarty MF, DiNicolantonio JJ. The molecular biology and pathophysiology of vascular calcification. Postgrad Med. 2014;126(2):54-64. https://doi.org/10.3810/ pgm.2014.03.2740

5. Grandi NC, Breitling LP, Brenner H. Vitamin D and cardiovascular disease: systematic review and meta-analysis of prospective studies. Prev Med. 2010;51(3-4):228-33. https://doi. org/10.1016/j.ypmed.2010.06.013

6. Artaza JN, Contreras S, Garcia LA, Mehrotra R, Gibbons G, Shohet $\mathrm{R}$, et al. Vitamin $\mathrm{D}$ and cardiovascular disease: potential role in health disparities. J Health Care Poor Underserved. 2011;22(4 Suppl):23-38. https://doi.org/10.1353/hpu.2011.0161
7. Maeda SS, Borba VZ, Camargo MB, Silva DM, Borges JL, Bandeira F, et al. Recommendations of the Brazilian Society of Endocrinology and Metabology (SBEM) for the diagnosis and treatment of hypovitaminosis D. Arq Bras Endocrinol Metabol. 2014;58(5):411-33. https://doi.org/10.1590/00042730000003388

8. Tchernof A, Després JP. Pathophysiology of human visceral obesity: an update. Physiol Rev. 2013;93(1):359-404. https:// doi.org/10.1152/physrev.00033.2011

9. Ohashi N, Yamamoto H, Horiguchi J, Kitagawa T, Hirai N, Ito $\mathrm{K}$, et al. Visceral fat accumulation as a predictor of coronary artery calcium as assessed by multislice computed tomography in Japanese patients. Atherosclerosis. 2009;202(1):192-9 https://doi.org/10.1016/j.atherosclerosis.2008.04.019

10. Hoffmann U, Massaro JM, D’Agostinho RB Sr, Kathiresan S, Fox CS, O’Donnell CJ. Cardiovascular Event Prediction and Risk Reclassification by Coronary, Aortic, and Valvular Calcification in the Framingham Heart Study. J Am Heart Assoc. 2016;22:5(2):e003144. https://doi.org/10.1161/JAHA.115.003144

11. McClelland RL, Chung H, Detrano R, Post W, Kronmal RA. Distribution of coronary artery calcium by race, gender, and age: results from the Multi-Ethnic Study of Atherosclerosis (MESA). Circulation. 2006;113(1):30-7. https://doi.org/10.1161/ CIRCULATIONAHA.105.580696 
12. Hoff JA, Chomka EV, Krainik AJ, Daviglus M, Rich S, Kondos GT. Age and gender distributions of coronary artery calcium detected by electron beam tomography in 35,246 adults. Am J Cardiol. 2001;87(12):1335-9. https://doi.org/10.1016/ s0002-9149(01)01548-x

13. Jang SY, Kim SM, Sung J, Cho SJ, Choe YH. Coronary artery calcium scores and cardiovascular risk factors in 31,545 asymptomatic Korean adults. Int J Cardiovasc Imaging. 2016;32(Suppl 1):139-45. https://doi.org/10.1007/s10554016-0892-2

14. Mamudu HM, Paul T, Veeranki SP, Wang L, Panchal HB, Budoff M. Subclinical atherosclerosis and relationship with risk factors of coronary artery disease in a rural population. Am J Med Sci. 2015;350(4):257-62. https://doi.org/10.1097/ MAJ.0000000000000548

15. Bandeira F, Griz L, Freese E, Lima DC, Thé AC, Diniz ET, et al. Vitamin $D$ deficiency and its relationship with bone mineral density among postmenopausal women living in the tropics. Arq Bras Endocrinol Metabol. 2010;54(2):227-32. https://doi. org/10.1590/s0004-27302010000200020

16. Maeda SS, Saraiva GL, Kunii IS, Hayashi LF, Cendoroglo MS, Ramos LR, et al. Factors affecting vitamin D status in different populations in the city of São Paulo, Brasil: the São Paulo vitamin D Evaluation Study (SPADES). BMC Endocr Disord. 2013;13:14. https://doi.org/10.1186/14726823-13-14

17. Kalkan GY, Gür M, Koyunsever NY, Şeker T, Gözükara MY, Uçar $\mathrm{H}$, et al. Serum 25-hydroxyvitamin D level and aortic intimamedia thickness in patients without clinical manifestation of atherosclerotic cardiovascular disease. J Clin Lab Anal. 2015;29(4):305-11. https://doi.org/10.1002/jcla.21770
18. Carrelli AL, Walker MD, Lowe H, McMahon DJ, Rundek $\mathrm{T}$, Sacco RL, et al. Vitamin D deficiency is associated with subclinical carotid atherosclerosis: the Northern Manhattan study. Stroke. 2011;42(8):2240-5. https://doi.org/10.1161/ STROKEAHA.110.608539

19. Chen S, Law CS, Gardner DG. Vitamin D-dependent suppression of endothelin-induced vascular smooth muscle cell proliferation through inhibition of CDK2 activity. J Steroid Biochem Mol Biol. 2010;118(3):135-41. https://doi.org/10.1016/j.jsbmb.2009.11.002

20. Li YC, Kong J, Wei M, Chen ZF, Liu SQ, Cao LP. 1,25 -Dihydroxyvitamin $D(3)$ is a negative endocrine regulator of the renin-angiotensin system. J Clin Invest. 2002;110(2):22938. https://doi.org/10.1172/JCI15219

21. Gast KB, den Heijer M, Smit JW, Widya RL, Lamb HJ, de Roos A, et al. Individual contributions of visceral fat and total body fat to subclinical atherosclerosis: the NEO study. Atherosclerosis. 2015;241(2):547-54. https://doi.org/10.1016/j. atherosclerosis.2015.05.026

22. Alvey NJ, Pedley A, Rosenquist KJ, Massaro JM, O'Donnell CJ, Hoffmann $U$, et al. Association of fat density with subclinical atherosclerosis. J Am Heart Assoc. 2014;3(4):e000788. https:// doi.org/10.1161/JAHA.114.000788

23. Ma WY, Yang CY, Shih SR, Hsieh HJ, Hung CS, Chiu FC, et al. Measurement of waist circumference: midabdominal or iliac crest? Diabetes Care. 2013;36:1660-6. https://doi.org/10.2337/ dc12-1452

24. See R, Abdullah SM, McGuire DK, Khera A, Patel MJ, Lindsy $\mathrm{JB}$, et al. The association of differing measures of overweight and obesity with prevalent atherosclerosis: the Dallas Heart Study. J Am Coll Cardiol. 2007;50(8):752-9. https://doi. org/10.1016/j.jacc.2007.04.066 